\title{
Review of Assessment, Evaluation, and Accountability in Adult Education
}

\author{
Sandra Ratcliff Daffron, Western Washington University (Emeritus)
}

Hill makes a compelling reason for adult educators to consider this book - she reports there have been no new textbooks on assessment, evaluation, and accountability specific to the field of adult education in the last decade. While that is true, evaluation, accountability and assessment is usually required of all adult educators, in the course of their day-to-day operations, whether it be teaching, management, administration, training or carrying out educational projects. While this lack of specific textbooks on evaluation, accountability and assessment directed to adult educators is a concern, the demands by those funding adult educational programs continue to expect and often to demand accountability. As Hill points out, adult educators have had to turn to other areas of practice such as training, student affairs, higher education, online learning, counseling, psychology, and special education to formulate evaluation plans to meet the demands of accountability. Indeed, those adult educators working in fields of adult basic education will hear, "Prove to us this student has progressed. How many grade levels have they moved upward in reading?" Moving up grade levels in reading doesn't always assess all

the progress a student makes. Or continuing professional educators are often faced with the comment, "Since you are an adult educator, produce a one-page evaluation form that effectively measures our program." This request comes from content experts who have not learned about evaluation and assessment and want a quick and simple measurement of the speaker's ability, the usefulness of materials, and the temperature of the coffee, food, and the meeting room. Those requesting such forms look at the score of each task to determine if the speaker is successful, the materials were adequate and if the speakers should be invited back to speak again. These scores are often used to prove to the program sponsors that the

Hill, L.H. (Ed). (2020). Assessment, Evaluation, and Accountability in Adult Education. Stylus. 263 pages, $\$ 35.00$, paperback.

ISBN: 9781620368510 
audience learned the intended objectives. Hill provides definitions and examples of evaluation, assessment, and accountability taken from a wide variety of articles and chapters from books, many which are current and others that have served as the basis of adult education teachings over the years.

This book is designed to provide a variety of evaluation, assessment, and accountability perspectives from the field of adult education. Each chapter is written by contributors representing the field who were challenged to describe and explain their approach to evaluation, assessment, and accountability. The very practical approach of the contributors, help the learner see that there is no "one size fits all" to evaluation and it is important and necessary to understand, measure, and assess learning. The book has 14 chapters with Part One introducing and defining program evaluation and learning assessment. Hill provides a comprehensive introductory chapter of the scope of evaluation, assessment, and accountability and the rubrics for measurement. While other adult education resources may offer these same rubrics, it is very helpful to have the scope of the field in one place in this book. Each chapter of the book has current research for graduate students to pursue. Part Two, Three and Four provide an array of assessment and evaluation practices in the field of adult education. The fields represented are adult literacy and adult basic education, professional military education, continuing professional education, licensed education (law, engineering, nursing, medicine) and other professions, human resource development (HRD), public service agencies (for building community capacity), health care in higher education, distance learning, competency based education and other delivery methods. The last part of the book focuses on higher education practices in the field of adult education.

\section{Evaluation and Recommendation}

With such a broad scope to include all types of evaluation and to see how the types of evaluation, assessment. and accountability are tied to the broad field that comprises adult education, the reader would wonder how this is even possible. Does the book meet such a broad purpose? To find the answer to that question, one must turn to the chapters to see how the authors approach their challenge.

For those teaching Adult Basic Education $(\mathrm{ABE})$, accountability is tied to funding and the government funding measures success with scores. This chapter explains the tests used: TABE, CASAS, BEST, the expectations of workforce students and the best instruments to assess and diagnose. Note: I wish I had this chapter when teaching Life Skills and conducting staff development for ABE and ESL teachers.

Another chapter lays out the assessment and evaluation measurements for continuing professional education (CPE). This chapter gives the reader a good background of the field with Houle, Cervero and Wilson, Daley, Mazmanian, Davis, Knox, Kirkpatrick, and others who have contributed so much to this area of practice. The tables and charts in the chapter pull the best practices together in one place. One statement helps to summarize the challenge facing CPE, "Although there is no singularly correct model for valuing or evaluating continuing professional education programs, the need for evaluation is undiminished” (p. 99). Note: I worked closely with many of these authors throughout most of my professional career and find the reader will benefit from the scope of the research in CPE in this chapter.

The chapter on distance education is a must read for all educators. Simone C.O. Conceicao 
is excellent in speaking about the evaluation, assessment, and accountability of distance education. Since the COVID-19 pandemic has thrown the world into chaos, educators have had to face the reality of teaching remotely whether they like it or not. Headlines have screamed about the inadequate use of distance education, the children who have lost a year of knowledge and skills because distance learning was no better than no learning at all. Just ask any parent and grandparent and they immediately become experts on distance education, and they can tell you how terrible it has been for their children. Those of us who have used distance education know there is great value in teaching this way and the future will undoubtedly incorporate virtual learning, virtual meetings, and virtual communication in all types of education and training. Distance education will not go away, therefore, educators ought to make the effort to learn to teach with this method effectively and with creativity. Conceicao provides examples and guidance for measurement of this method of teaching. Again, I wish I had this chapter when I taught adult education courses through e-learning.

To summarize my review of this book on evaluation, assessment, and accountability, I wish I would have had this book to hand to my ABE colleagues and my graduate students. When teaching evaluation classes, I used a collection of articles, chapters of books and my own experience. Students brought in the instruments they used with their professions, and most were check sheets to measure the speaker, the materials, the comfort of the room and the temperature of the coffee. This book is like a "one stop shopping." It will appeal to the educators from the broad field of adult education with very practical applications supported by recent research. I give it a hearty "thumbs up!" 